\title{
Modelagem Digital, Prototipagem e Ensino de Arquitetura e Urbanismo: Impactos e Desdobramentos de uma Intervenção Curricular
}

\author{
Digital Modeling, Prototyping and Teaching Architecture and Urbanism: Impacts and Consequences Of \\ A Curriculum Intervention
}

\author{
Frederico Braida Rodrigues de Paula \\ Universidade Federal de Juiz de Fora, Brasil \\ frederico.braida@ufjf.edu.br \\ Fernando Tadeu de Araújo Lima \\ Universidade Federal de Juiz de Fora, Brasil \\ fernando.tadeu@ufjf.edu.br
}

\begin{abstract}
This article aims to describe the experience developed within the course entitled Modeling and Digital Prototyping, offered by the Architecture and Urbanism of the Federal University of Juiz de Fora. We focus the impacts and consequences of a curriculum intervention that values the digital graphic as the possibility of development of architecture and urbanism in contemporary society.
\end{abstract}

Keywords: Digital modeling; Teaching Architecture; Rapid Prototyping; Virtual Prototyping.

\section{Introdução}

Este artigo tem por objetivo apresentar, de forma crítica e reflexiva, os resultados decorrentes da implantação da disciplina "Modelagem digital e prototipagem" no Curso de Arquitetura e Urbanismo de uma Universidade Federal de Juiz de Fora (UFJF) dentro do ciclo de fundamentação da matriz curricular obrigatória. O presente trabalho é decorrente tanto de uma pesquisa levada a cabo pelos professores da área de Meios de Expressão e Representação e da área de Projeto do Departamento de Arquitetura e Urbanismo da referida Instituição, especialmente por aqueles vinculados ao Grupo de Pesquisa das Linguagens e Expressões da Arquitetura, Urbanismo e Design (LEAUD), a qual fundamentou a inserção do conteúdo de modelagem digital e prototipagem em uma disciplina específica, quanto da avaliação dos alcances, impactos e projeções pedagógicas dessa intervenção curricular.

As considerações tecidas no artigo giram em torno de três categorias analíticas e conceituais fundamentais: (1) a contribuição da gráfica digital no ensino e na produção da arquitetura contemporânea, (2) as tipologias possíveis da inserção da gráfica digital na matriz curricular de um Curso de Arquitetura e Urbanismo e, por fim, (3) a mídia digital como suporte de registro do processo de projeto, de modelagem e de fabricação arquitetônica. A partir da correlação entre tais categorias (ou temas de análise e discussão), além de se obter alguns parâmetros predominantes e vigentes da incorporação da gráfica digital nos cursos de Arquitetura e Urbanismo, vislumbra-se um cenário em que as novas tecnologias de informação e comunicação já não se apresentam apenas como ferramentas de representação, mas são solicitadas em todas as fases projetuais, impactando a linguagem contemporânea da arquitetura, seja no nível sintático, semântico ou pragmático.

Portanto, elencam-se algumas possibilidades da inserção da gráfica digital dentro de uma proposta metodológico-pedagógica para o ensino da arquitetura, urbanismo e paisagismo na contemporaneidade, evidenciando-se as tipologias de incorporação das tecnologias digitais nos processos de projeto e de ensino do mesmo. Por fim, exploram-se os aspectos cognitivos e as possibilidades de registros das ações projetuais, em todas as suas fases, derivados da adoção da mídia digital como substrato lógico de concepção, de desenvolvimento e de apresentação de um objeto arquitetônico.

De acordo com Pupo (2008), os cursos de arquitetura têm tentado incorporar em suas disciplinas de projeto cada vez mais as tecnologias CAD. No Brasil, essas tecnologias têm sido introduzidas de maneira isolada, frequentemente como cursos extracurriculares, no intuito de proporcionar ao discente uma base simples para a futura inserção no mercado de trabalho. Entretanto, ainda segundo Pupo (2008), nota-se em países da Europa, em algumas escolas, um esforço para integrar a utilização dos computadores com o atelier de projeto. Ao discutir sobre a estruturação curricular, Mark et al. (2000; 2001) afirma que o currículo ideal seria aquele que traz a tecnologia do computador para dentro de cursos já existentes, de maneira gradativa, mas ao 
mesmo tempo olha para os métodos de ensino de projeto, como um agente promotor da mudança de panorama nas áreas de metodologia e teoria de projeto.

Nesse contexto destacam-se a criação dos laboratórios de modelagem virtual, de prototipagem e de fabricação digital, os quais, recorrentemente vinculados a algum grupo de pesquisa, incorporam as características das oficinas de maquetes e modelos, dos ateliês e laboratórios de projeto e, em alguns casos, de pequenas indústrias, hibridizando-as em um único espaço de produção do conhecimento. Assim, constata-se que, mesmo timidamente, as universidades brasileiras, desde meados da primeira década deste século, vêm incorporando as tecnologias da modelagem digital e da prototipagem, o que repercute nas mudanças de alguns dos paradigmas do ensino de projeto nos cursos de Arquitetura e Urbanismo, uma vez que se tem, agora, o próprio modelo como uma memória do projeto.

Espera-se, portanto, com este artigo, contribuir com algumas reflexões sobre as possibilidades de incorporação dos conteúdos relacionados à modelagem paramétrica e algorítmica, prototipagem rápida e simulação virtual no âmbito da graduação, analisando seus desdobramentos, compartilhando experiências e discutindo sobre as transformações no conteúdo da formação do arquiteto e urbanista na contemporaneidade, sobre o ensino e a memória do projeto.

\section{Desenvolvimento da Disciplina}

A disciplina intitulada Modelagem Digital e Prototipagem se insere como obrigatória na nova grade curricular do curso de arquitetura e urbanismo da Universidade Federal de Juiz de Fora, estando programada para ser cursada no terceiro período. Entretanto, por estar sendo oferecida pela primeira vez no semestre 2013/1 e por demandar como pré-requisitos todas as disciplinas obrigatórias da área de representação e expressão, a disciplina foi cursada por alunos que se encontravam em diversos períodos, excepcionalmente no semestre em questão, em especial alunos do quinto e sexto períodos.

\section{Ementa, programa e módulos}

A disciplina proposta possui como ementa a abordagem da Prototipagem virtual, simulação e fabricação digital. Fundamentos, conceituações e ferramentas para a prototipagem virtual, simulações e Fabricação digital. Aplicações da prototipagem virtual e da simulação no Processo de concepção, desenvolvimento e representação de projeto de Arquitetura e urbanismo. Deste modo, como programa a disciplina apresenta: (a) introdução à manipulação digital, panorama sobre tecnologias e ferramentas auxiliares ao processo de produção arquitetônica; (b) Apresentação de programas de modelagem paramétrica; (c) prototipagem virtual em seus conceitos e fundamentação; (d) modelagem paramétrica de protótipos visando simulações; (e) fabricação digital em seus conceitos e fundamentação; (f)
Métodos de fabricação digital: aditiva, subtrativa e formativa; (g) modelagem para a fabricação.

Desse modo, a disciplina foi pensada e estruturada de maneira a se constituir por aulas essencialmente práticas, com base em exposições de comandos e instruções a serem aplicadas pelos alunos em sala de aula. Em que a cada início de Módulo, há uma aula teórica, que objetiva contextualizar as atividades a serem conduzidas, apresentar os conceitos a serem utilizados e direcionar pesquisas e buscas por tutoriais a serem feitas. Cabe ainda ressaltar a existência de um trabalho final que objetiva a aplicação prática dos conteúdos da disciplina.

Sendo assim, as 16 semanas de aula foram dividas em 4 módulos organizados da seguinte maneira: (a) módulo I - conceitos e fundamentos relativos ao pensamento digital em arquitetura; (b) módulo II - modelagem tridimensional no Rhinoceros; (c) módulo III - Grasshopper; (d) módulo IV - trabalho final - experimentos práticos.

No módulo I, o objetivo foi o de difundir e apresentar conceitos, ferramentas e possibilidades de utilização da informática na pesquisa em arquitetura, os novos meios de geração e produção e toda a temática relativa a este contexto. Ao final deste módulo os alunos apresentaram em um seminário trabalhos com os temas: geometria topológica; algoritmo e desenho algorítmico; arquitetura paramétrica e generativa; emergência; gramática da forma; geometria fractal e biomimética.

De uma maneira geral, podemos afirmar que o resultado deste primeiro módulo e de seu seminário foi extremamente satisfatório, uma vez que os alunos se viram diante de temas até então desconhecidos (ou de pouco conhecimento), mas que ao mesmo tempo despertaram neles o interesse por questões relativas à disciplina.

No segundo módulo, foram trazidos os conteúdos relativos à modelagem tridimensional em ambiente Rhinoceros, por meio da Introdução à interface do software, seus recursos e comandos básicos, além da Modelagem de sólidos e superfícies - NURBS, operações geométricas,finalizações, acabamentos e render. Não se trata de um curso do software, até por restrições de tempo e de proposta da disciplina, mas a intenção é a de introduzir os alunos a esta ferramenta que é utilizada no decorrer da disciplina e esperase deles a busca por complementar o que é dado em sala de aula com a prática extraclasse.

No terceiro módulo, foram trazidas questões referentes à modelagem generativa e paramétrica, mais especificamente o plug-in Grasshopper associado ao Rhinoceros. Nesta etapa, foram encontradas maiores dificuldades, em virtude da lógica de trabalho do ambiente em questão e da necessidade de se desenvolver um repertório de comandos para o trabalho. Dessa maneira, os exercícios foram trazidos sob a forma de tutoriais e conforme as tarefas eram executadas, os próprios alunos foram associando comandos e propondo alternativas e modelos. 

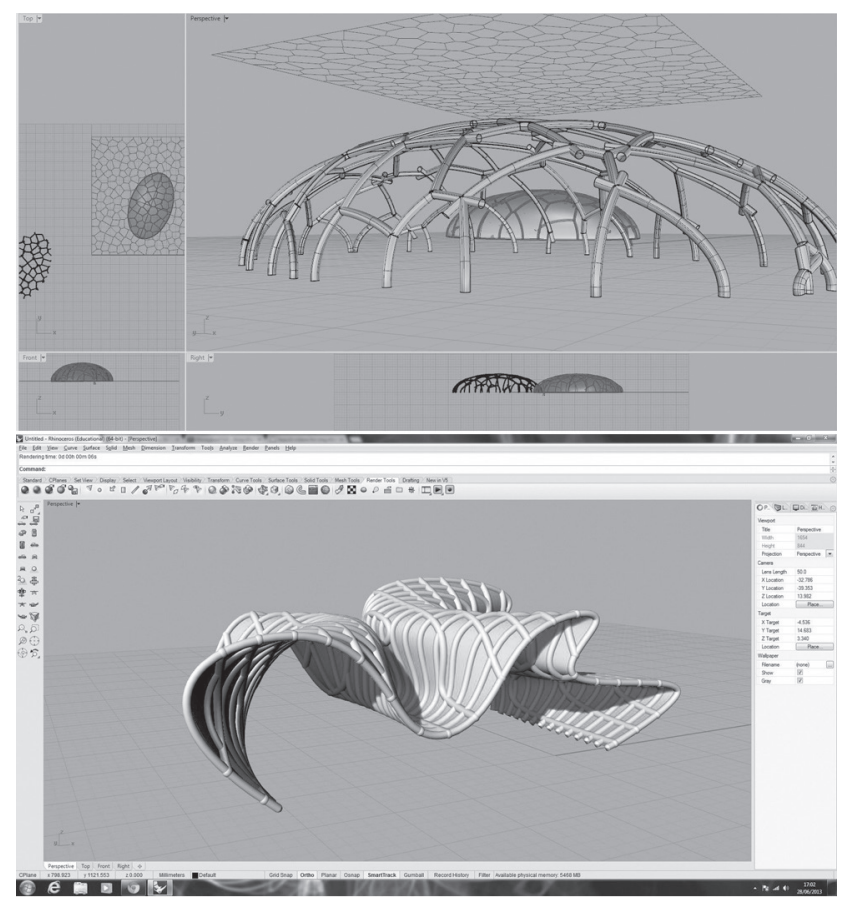

Figura 1: Imagens de modelos desenvolvidos por alunos em sala de aula e extraídas do grupo da disciplina em rede social.

O quarto e último modulo da disciplina Modelagem digital e prototipagem consistiu no desenvolvimento de um Trabalho Final. Para tanto, os alunos foram divididos em grupos para elaborar e desenvolver um trabalho que utilizasse os recursos e conhecimentos adquiridos no semestre e que resultasse em um produto a ser avaliado. Assim, após formados os grupos, os alunos tiveram os momentos de sala de aula para discutir a proposição, modelagem e execução de um produto final que fosse digitalmente concebido e elaborado de acordo com as técnicas e recursos transmitidos ao longo do período, com o auxílio dos professores e do bolsista disponível e que auxiliou a execução dos trabalhos. Entre os temas possíveis escolhidos pelos alunos para o desenvolvimento deste trabalho estavam: (a) a elaboração de mobiliário; (b) criação de adesivo de recorte com tema gerado digitalmente; (c) esculturas digitalmente geradas.

\section{A disciplina e a rede social}

Outra iniciativa que se mostrou válida foi a criação de um grupo específico da disciplina na rede social. Situado no Facebook, o grupo da disciplina começou como um canal de comunicação entre alunos e professores sobre questões práticas da disciplina, passou a conter postagens sobre os seminários e trabalhos feitos em sala e atualmente possui as mais diversas informações sobre impressão $3 d$, modelagem digital, parametrização e temas relacionados à disciplina, agregando, inclusive, membros que são professores e alunos de outras instituições, o que tem constituído este grupo como uma espécie de fórum sobre as questões sobre arquitetura e informática.
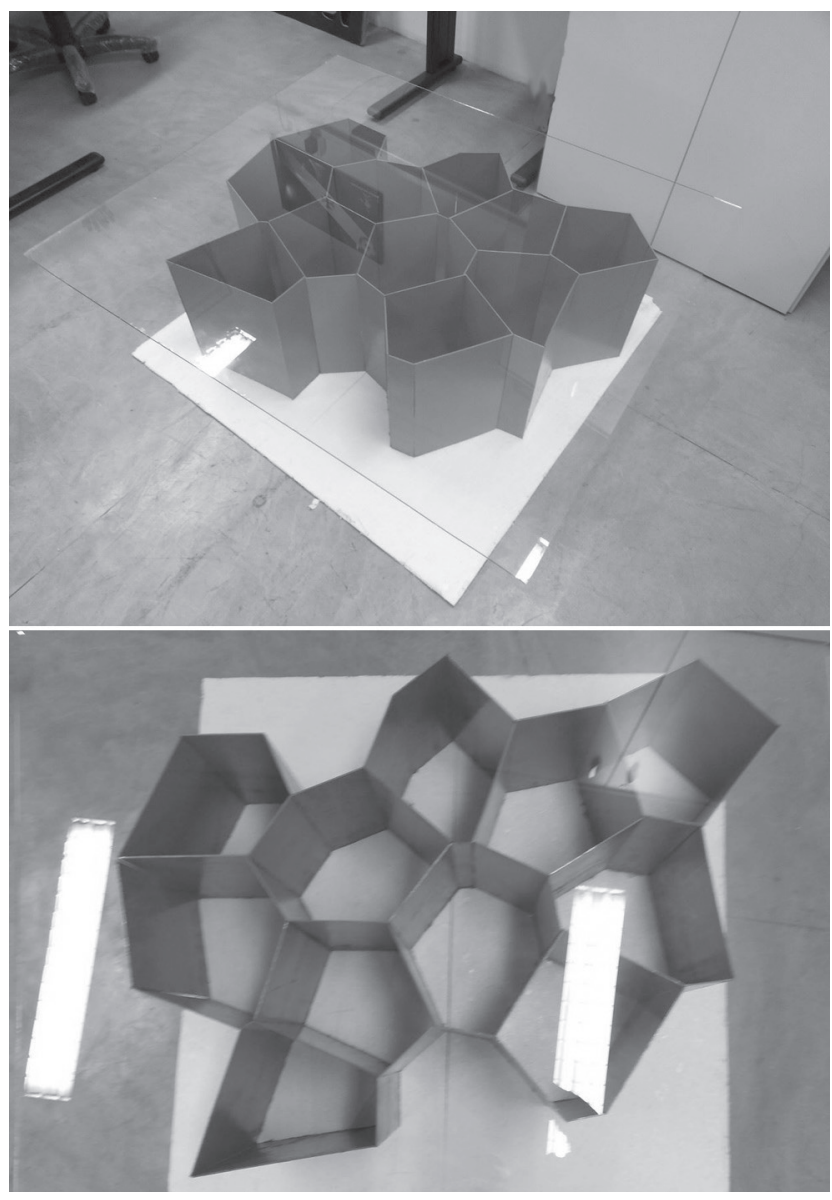

Figura 2: Imagens de um dos trabalhos finais entregues, uma mesa de centro com base feita pela extrusão de diagrama de voronoi e tampo de vidro.

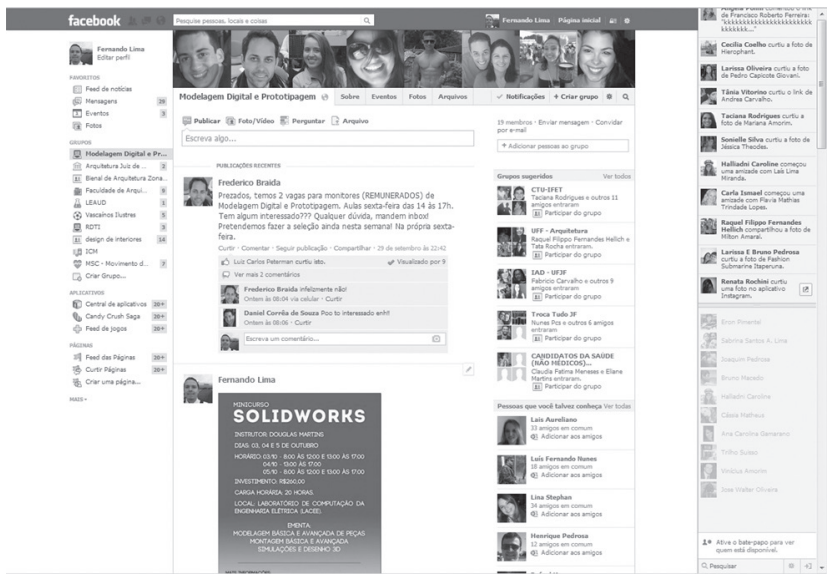

Figura 3: O grupo da disciplina no facebook.

\section{Resultados obtidos}

Apesar de estar em seu primeiro ano de implementação, já se pode observar alguns resultados decorrentes da introdução da disciplina Modelagem digital e prototipagem na esfera do curso de arquitetura e urbanismo da UFJF. Dentre eles destacam-se: (1) o crescente interesse por temas ligados à cultura digital e arquitetura, (2) o surgimento de projetos de pesquisa em iniciação 
científica com boa procura por parte dos alunos e (3) uma maior utilização de softwares de modelagem tridimensional como suporte à concepção e metodologia de projeto. Por fim, vislumbrase um cenário em que as novas tecnologias de informação e comunicação já não se apresentam apenas como ferramentas de representação, mas são solicitadas em todas as fases projetuais, de maneira a contribuir para o processo de projeto dos alunos.

\section{Considerações Finais}

Os cursos de arquitetura têm tentado incorporar em suas disciplinas de projeto cada vez mais as tecnologias CAAD. No Brasil, essas tecnologias têm sido introduzidas de maneira isolada, frequentemente como cursos extracurriculares, no intuito de proporcionar ao discente uma base simples para a futura inserção no mercado de trabalho.

O esforço e as iniciativas relatadas aqui fazem parte de um conjunto de iniciativas no âmbito do curso de arquitetura e urbanismos da Universidade Federal de Juiz de Fora, que em sua reformulação curricular procura trazer a tecnologia do computador para dentro de sua estrutura, de maneira gradativa, mas ao mesmo tempo olhando para os métodos de ensino de projeto, como agentes promotores da mudança de panorama nas áreas de metodologia e teoria de projeto.

Nesse contexto destacam-se a criação dos laboratórios de modelagem virtual, de prototipagem e de fabricação digital, os quais, recorrentemente vinculados a algum grupo de pesquisa, incorporam as características das oficinas de maquetes e modelos, dos ateliês e laboratórios de projeto e, em alguns casos, de pequenas indústrias, hibridizando-as em um único espaço de produção do conhecimento. Neste sentido, constata-se que, mesmo timidamente, as universidades brasileiras, desde meados da primeira década deste século, vêm incorporando as tecnologias da modelagem digital e da prototipagem, o que repercute nas mudanças de alguns dos paradigmas do ensino de projeto nos cursos de Arquitetura e Urbanismo.

\section{Agradecimentos}

Agradecemos, aos alunos envolvidos na disciplina e nas práticas relatadas neste artigo, a Pró-Reitoria de Pesquisa da Universidade Federal de Juiz de Fora- PROPESQ/UFJF e à Fundação de Amparo à Pesquisa do Estado de Minas Gerais - FAPEMIG.

\section{Referências}

Grimm, T. (2005). Virtual Versus Physical: will computer-generated virtual prototypes obsolete rapid prototyping? Time-Compression Technologies.

Mark, E., Martens, B., \& Oxman, R. (2000). The Ideal Computer Curriculum. In Anais do 19 eCAADe, 168-175.

. Theoretical and Experimental Issues in the Preliminary Stages of Learning/Teaching CAAD. In: Anais do 21 eCAADe, 2002. p.205-212.

Mitchell W. J. (2008) A lógica da arquitetura: projeto, computação e cognição. Trad: Gabriela Celani. Campinas, SP: Ed. Unicamp.

Pupo, R. (2008). Ensino da prototipagem rápida e fabricação digital para arquitetura e construção no Brasil: definições e estado da arte, Revista eletrônica PARC-UNICAMP, 1 (5),1-19.

Ulrich, K. T. Eppinger, S. D. (2000). Product Design and Development. London: McGraw-Hill. 